\title{
Multi-model synthesis of future extreme temperature indices over Zambia
}

\author{
Brigadier Libanda ${ }^{1}$ (1)
}

Received: 30 October 2019 / Accepted: 2 March 2020 / Published online: 11 March 2020

(c) The Author(s) 2020

\begin{abstract}
Although temperature is one of the most important climate variables to be considered in adapting systems to climate change, its study over Zambia has until recently been largely ignored. A dearth of the literature on future temperature extremes is especially apparent. For the first time, future extreme temperature variability is analysed in Zambia for the period 1961-2100. The nonparametric Mann-Kendall test statistic is used at 5\% significant level to compute trends. Sen's slope estimator is used to give the magnitude of the observed trends. A two-tailed Kolmogorov-Smirnov statistical test is used to calculate the significance of the observed changes. What stands out from the findings is that warm days and nights become warmer while cool days and nights are projected to become non-existent by 2100 . Additionally, an increase in radiative forcing and time is seen to intensify extreme temperature events. Notably, much of southern Zambia is projected to experience $\sim 30 \%$ increment in TX90p while the northern half will experience $~ 40 \%$ under RCP4.5 by the middle of the century (2021-2050). If the business-as-usual trajectory (RCP8.5) is followed, an intensification of TX90p is observed with 40\% in the southern half of the country and $\sim 50 \%$ in the northern half. These projections are observed to almost double towards the end of the century (2071-2100). The projected increase in warm nights (TN90p) is more over Luapula and Northwestern province while the lowest is observed over the Livingstone/Magoye region. These results provide a foundation for strategic planning purposes to avert losses related to extreme temperature.
\end{abstract}

Keywords Climate change $\cdot$ Temperature extremes $\cdot$ CMIP $5 \cdot$ Zambia

\section{Introduction}

During the last two decades, the link between climate change and extreme events has been at the centre of much attention (IPCC 2012; Ongoma et al. 2018). Climate change is of interest to the study of extreme events (IPCC 2007) such as heatwaves and heat stress. In climate change science, temperature is one of the most important variables (Easterling et al. 2000); its statistical linkages to various aspects of the hydrological cycle are well documented (Held and Soden 2006). A rise in temperature at the global scale has led to the mushrooming of the global warming terminology. Global warming is an increasingly important area in climate change science; this is because warming boosts sea level rise

Brigadier Libanda

brigadier.libanda@ed.ac.uk;

brigadierlibanda@rocketmail.com

1 School of Geosciences, The University of Edinburgh, Edinburgh EH9 3FF, UK via thermal expansion of the oceans, melting of glaciers, and ice-sheets (Gerald et al. 2005) consequently increasing the risk of storm surge (Karim and Mimura 2008) and the transportation of brackish water inland, potentially affecting eight of the world's largest coastal cities (UN 2002). All these lead to disruptive storm surges, flooding and shoreline erosion (Zhang et al. 2004; Masselink and Russell 2013). Further, a warm atmosphere has a larger moisture holding capacity which results in more intense rainfall (Libanda and Chilekana 2018).

Temperature rise is also associated with heat waves (Meehl and Tebaldi 2004). Heat waves can cause catastrophic impacts (Patz et al. 2005) and even death in some cases (Huynen et al. 2001). Heat waves have been reported to result in shortages of water supply (Koch and Vögele 2009) and consequently increased electricity load shedding (Hill 2016). Cases of heat strokes are also commonly reported around the world whenever a heat wave strikes (Patz et al. 2005). While understanding the complexity of heat waves is vitally important, there is no consensus in the 
literature on the definition of the heat wave term because of the spatial-temporal variability of temperature around the world. The Dutch use the temperature in De Bilt town as a yardstick; they, thus, classify prolonged high temperature with humidity as a heat wave only if the period under consideration is a minimum of 5 days in which temperatures exceeding $25{ }^{\circ} \mathrm{C}$ have been observed. De Bilt town should experience temperatures exceeding $30{ }^{\circ} \mathrm{C}$ during at least 3 of these 5 days (Porja 2013). Generally, in the USA the heat wave terminology is used as soon as excessively high temperatures are experienced for a minimum of 2 days (Porja 2013). One well-known definition that is often cited in research as an acceptable classification of heat waves is that of the World Meteorological Organization (WMO), which defined a heatwave as the occurrence of daily maximum temperature exceeding $5{ }^{\circ} \mathrm{C}$ of the average for at least 5 consecutive days (WMO 2015).

In recent years, much more information has become available on the statistical linkages between temperature and evapotranspiration. For example, an increase in temperature has been associated with increased evapotranspiration consequently drier than normal soils (Falamarzi et al. 2014). This often leads to a fall in agricultural production and thus food insecurity.

In light of temperature changes (IPCC 2001), fire (intensity and/or frequency) regimes are also documented to potentially change in the future and these disturbances will have a telling effect on tree growth (Dale et al. 2001). The findings of Hatfield (Hatfield and Prueger 2015) in a study on the impacts of temperature extremes on the growth of plants show that increase in temperature will potentially reduce plant productivity. Their findings further showed that temperature increments reduced maize yield by as much as 80-90\% when compared to a normal temperature regime.

The fishing industry, a significant economic-stronghold for many people in Africa, is also negatively impacted by temperature increase; this is because thermal expansion of water damages the structure and function of aquatic ecosystems (Daw et al. 2009; Brander 2007). Temperature rise also leads to the destabilisation of coral reefs (Spalding and Brown 2015) which play an important role in the tourism sector.

With continued active anthropogenic activities, at a global scale, average temperatures are projected to increase by more than $2{ }^{\circ} \mathrm{C}$ towards the end of the century (Fuss 2010). A recent study by WMO shows that at $1.1^{\circ} \mathrm{C}$ above pre-industrialization temperatures, 2017 was the warmest year without the short-term warming influence of El Nino (WMO 2017) and the year 2016 remains the warmest owing to the short-term influence exerted by El Nino.

The impacts of temperature extremes are already being felt in Zambia and changes in climate-sensitive sectors are widely reported, for example, the drying up of Lake Kariba
(Hill 2016), agrometeorological drought (Chaudhury et al. 2011) and intense precipitation (Libanda et al. 2016). All these studies illustrate aspects with linkages to extreme temperature consistent with this contribution. It, therefore, cannot be argued that understanding variations of temperature extremes marks the starting point for the predictability and eventual safeguard from climate change induced extreme events.

While studies (Mason and Joubert 1997; Diallo et al. 2012; Sylla et al. 2013) have been done to give projections of climate extremes over Africa, these are usually generalized at the continent or regional level without due focus on small local areas. A primary concern of extreme events is their destructive nature at the local scale. It follows then that projections focussing on the local- and individual countryscale are imperative. Country level projections better inform decision-making processes. The work embodied in this paper focuses on Zambia and on extreme temperature for the period 1961-2100. To better understand these extreme temperature dynamics, two representative concentration pathways (RCP; IPCC 2014) have been adopted in this work, i.e., RCP4.5 and RCP8.5. RCPs classify projections in 4 distinct possible states of the climate depending on emitted greenhouse gasses and these include RCP2.6, RCP4.5, RCP6, and RCP8.5. A good summary of the classification of RCPs has been provided in the work of Taylor et al. (2012).

\section{Data and methodological approach}

\section{Study area}

Zambia is a southern African country whose climatology is best described as subtropical although, because of its high elevation, much of the country experiences lower temperatures compared to other tropical countries (Libanda et al. 2019). During the summer, temperatures average $28^{\circ} \mathrm{C}$ and drop to as low as $5{ }^{\circ} \mathrm{C}$ in the winter (Hachigonta and Reason 2006). In early summer, temperatures over much of Zambia usually drop under Guti conditions (sensu Shoko and Shoko 2013). These conditions are often associated with stratified type of clouds and occasional drizzle. These conditions are seasonal and are documented to be propagated by easterly winds that bring in cool and stable maritime air as a result of a passing anticyclone towards the southeast affecting Zimbabwe and parts of Zambia (Huygen 1989). Figure 1 shows the geographical location of Zambia on the map of Africa.

\section{Data}

The Expert Team on Climate Change Detection and Indices (ETCCDI) as suggested in the work of Karl et al. (1999) which were also found useful by Dietzsch et al. 


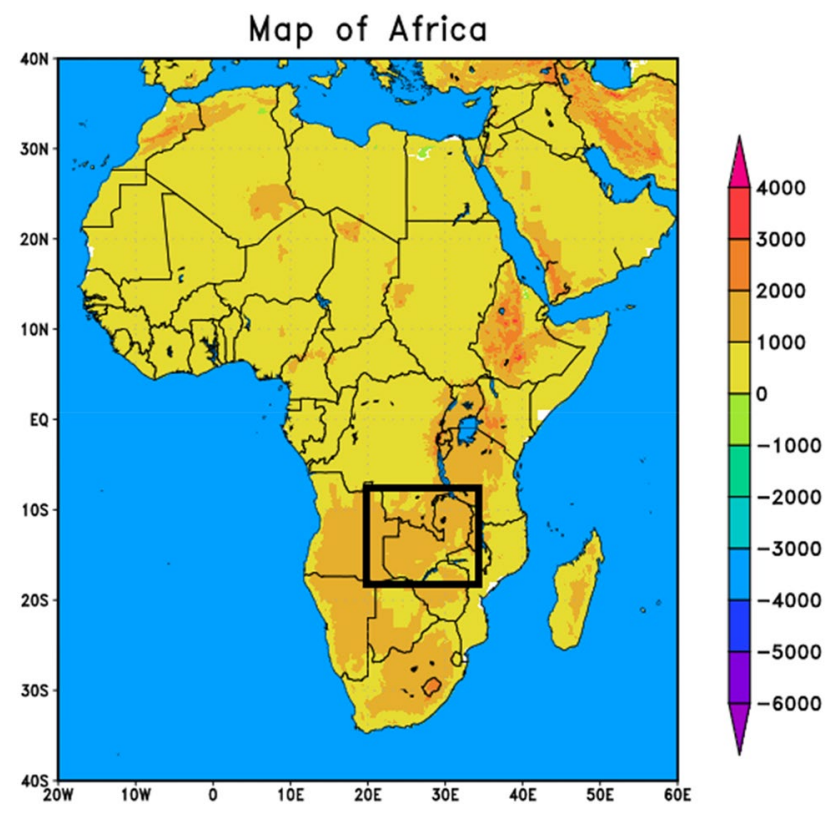

Fig. 1 Topographical map of Africa showing the location of Zambia (black square). Blue shows major water bodies

(2017) across the globe and more recently by Nkunzimana et al. (2019) in Burundi is used in this study. Data of extreme temperature as simulated by CMIP5 models in the historical run 1850-2005 and projections covering 2006-2100 is utilized. Details of this data are provided in the work of Sillmann et al. (2013). Table 1 shows a pool of 18 models which were assessed on their ability to simulate temperature over Zambia. Top performing models were selected and included in an ensemble which was used to carry out this study. The remaining models were discarded. The selection of models was based on correlation coefficient $(R)$, root-mean-square error (RMSE), and bias.

Other studies have preferred to use Regional Climate Models (RCMs) over General Circulation Models (GCMs). However, the argument in this work is that whereas the justification to use RCMs is appreciated, the need to decipher the performance of GCMs over Africa is still imperative as they are used to drive RCMs (Dosio 2016). In fact, an earlier study by Dosio and Panitz (2016) found that sometimes, RCMs fail to improve the results of the driving GCMs as they inherit their bias through the lateral boundary conditions that are added to RCMs.

Climate Research Unit Timeseries version 4.01 (CRU TS v4.01) a product of the Climate Research Unit of the University of East Anglia was used as a surrogate for station temperature data to assess the ability of models to simulate temperature over Zambia. CRU TS v4.01 covers the period 1901 to near present and is gridded at a horizontal resolution of $0.5^{\circ} \times 0.5^{\circ}$. A complete description of the CRU data is provided by Harris et al. (2014).

Figure 1 was generated using $1^{\circ}$ latitude-longitude resolution elevation dataset from the Joint Institute for the Study of the Atmosphere and Ocean (JISAO). JISAO is a US-based institute which specializes in atmospheric sciences and mainly collaborates scientific work between the National Oceanic and Atmospheric Administration (NOAA) and the University of Washington. Details of

Table 1 CMIP5 models used in this study

\begin{tabular}{llc}
\hline Model name & Modelling institution & Lat $\times$ Lon \\
\hline BCC-CSM1-1-M & Beijing Climate Centre, China Meteorological Administration, China & $2.8^{\circ} \times 2.8^{\circ}$ \\
BNU-ESM & College of Global Change and Earth System Science, Beijing Normal University & $2.8^{\circ} \times 2.8^{\circ}$ \\
CCSM4 & National Centre for Atmospheric Research, USA & $\sim 0.9^{\circ} \times 1.3^{\circ}$ \\
CESM1-CAM5 & National Center for Atmospheric Research, USA & $1.25^{\circ} \times 0.9^{\circ}$ \\
CNRM-CM5 & Centre National de Recherches Météorologique, France & $\sim 1.4^{\circ} \times 1.4^{\circ}$ \\
CSIRO-MK3.6.0 & Commonwealth Scientific and Industrial Research Organization, Australia & $\sim 1.875^{\circ} \times 1.875^{\circ}$ \\
EC-EARTH & Royal Netherlands Meteorological Institute, Netherlands & $1.125^{\circ} \times 1.125^{\circ}$ \\
FGOALS-g2 & Chinese Academy of Sciences, China & $2.79^{\circ} \times 2.81^{\circ}$ \\
FIO-ESM & The First Institute of Oceanography, China & $\sim 2.8^{\circ} \times 2.8^{\circ}$ \\
GFDL-ESM-2G & Geophysical Fluid Dynamics Laboratory, USA & $2.5^{\circ} \times \sim 2.0^{\circ}$ \\
GISS-E2-H & NASA Goddard Institute for Space Studies, USA & $2^{\circ} \times \sim 2.5^{\circ}$ \\
HadGEM2-ES & Met Office Hadley Centre, UK & $1.875^{\circ} \times 1.275^{\circ}$ \\
IPSL-CM5A-LR & Institut Pierre Simon Laplace, France & $3.75^{\circ} \times 1.8^{\circ}$ \\
MIROC5 & Atmosphere and Ocean Research Institute, The University of Tokyo, Japan & $1.4^{\circ} \times 1.4^{\circ}$ \\
MPI-ESM-LR & Max Planck Institute for Meteorology, Germany & $1.875^{\circ} \times 1.875^{\circ}$ \\
MPI-ESM-MR & Max Planck Institute for Meteorology, Germany & $1.875^{\circ} \times 1.875^{\circ}$ \\
MRI-CGCM3 & Meteorological Research Institute, Japan & $1.125^{\circ} \times 1.125^{\circ}$ \\
NOR-ESM1-ME & Norwegian Climate Centre & $2.5^{\circ} \times 1.8^{\circ}$ \\
\hline
\end{tabular}


their work are available on their website: https://jisao.uw. edu/.

\section{Methodological approach}

\section{Mann-Kendall test}

Given the importance associated with trend analyses in hydroclimatological research, many techniques have previously been proposed for trend analysis. However, the Mann-Kendall test statistic is widely used (Pohlert 2016) by both Hydrologists (Yue et al. 2002) and Climatologists (Fallmann et al. 2017). The Mann-Kendall is a nonparametric test statistic, and it has been used in this study after Mann (Mann 1945) and Kendall (Kendall 1975), to detect trends in extreme temperature changes in Zambia. The hypothesis followed in this study is:

$H_{0} \quad$ No monotonic trend found in temperature

$H_{a} \quad$ Monotonic trend is present in temperature

The computation of the Mann-Kendall test is mathematically given as:

$s=\sum_{i=1}^{n-1} \sum_{j=i+1}^{n} \operatorname{sig}\left(x_{i}-x_{j}\right)$

From this formula, $n$ is the sample size $X_{i}$ and $X_{j}$ are sequential values of $X$ and sig is:

$\operatorname{sig}(x) \begin{cases}1 & \text { if } x>x_{i} \\ 0 & \text { if } x=x_{i} \\ -1 & \text { if } x<x_{i}\end{cases}$

From Eq. 1, the variance of $S$ is given as:

$\operatorname{VAR}(S)=\frac{1}{18}\left[n(n-1)(2 n+5)-\sum_{p-1}^{g} t_{p}\left(t_{p}-1\right)\left(2 t_{p}+5\right)\right]$

where $g$ is the number of tied groups, $n$ is the number of data points, and $t_{p}$ is the number of observations in the $p$ th group. The parameters $s$ and $n$ are used to investigate the significance of the trend which is associated with the $Z$ value. An upward trend is shown by a positive score of the $Z$ value. Conversely, a downward trend is shown by a negative score of the $Z$ value. Mathematically, the $Z$ value is calculated as:

$$
\begin{aligned}
Z & =\frac{s-1}{\sqrt{\operatorname{Var}(s)}} \text { if } s>0 \\
& =0 \text { if } s=0 \\
& =\frac{s+1}{\sqrt{\operatorname{Var}(s)}} \text { if } \quad s<0
\end{aligned}
$$

Here, if the $Z$ value is negative and the calculated probability if more that the set level of significance (in this case 95\%), the trend is taken to be negative.

\section{Sen's slope estimator}

A nonparametric Sen's slope estimator was used to compute the magnitude of the trends. The Sen's slope calculates both the linear rate of change and associated confidence levels (Sen 1985). It is expressed as:

$Q=\frac{Y_{i^{\prime}}-Y_{i}}{i^{\prime}-i} \quad$ if $i^{\prime}>i$

Here, $Y_{i}^{\prime}$ and $Y_{i}$ are the values at times $i^{\prime}$ and $i$, respectively. The Sen's slope estimator calculates the median of the given $N$ values of the slope $(Q)$. The median of the $N$ slope estimates is then calculated using simple averaging. $N$ values of $Q_{i}$ are then ranked in ascending order, and the Sen's estimator is determined using Eq. 6

$\left\{\begin{array}{ll}Q\left[\frac{N+1}{2}\right] & \text { if } N \text { was odd } \\ \frac{1}{2}\left(Q_{\frac{N}{2}}+Q_{[(N+2) / 2]}\right) & \text { if } N \text { was even }\end{array}\right\}$

\section{Kolmogorov-Smirnov test}

Probability density functions (PDFs) of temperature intensity were constructed using empirical distribution. The changes in the shapes and upper limits of the PDFs were used to inform temperature changes. These temperature changes were further investigated with regards to their statistical significance by the use of a two-tailed Kolmogorov-Smirnov test (K-S test). Kolmogorov-Smirnov test is a nonparametric test which is effective in computing the difference between the empirical distribution functions of the data under study and the cumulative distribution function (CDF; Jupp et al. 2010). It follows that given $N$, the points $Y_{1}, Y_{2}, \ldots, Y_{N}$ the empirical distribution function is thus given as:

$E_{N}=n(i) / N$

Here, $n(i)$ stands for the number of points less than $Y_{1}$ provided that the $Y_{1}$ points are ordered from smallest to largest value. As a step function, it is given to increase by $1 / N$ at the value of each ordered data point. The hypothesis used for the $\mathrm{K}-\mathrm{S}$ test is:

$H_{0} \quad$ The data follows a specified distribution

$H_{a}$ The data does not follow a specified distribution

Mathematically, the definition of K-S test follows: 
$D=\max _{1 \leq i \leq N}\left(\left(F\left(Y_{i}\right)-\frac{i-1}{N}, \frac{i}{N}-F\left(Y_{i}\right)\right)\right.$

where $D$ is the maximum difference between two cumulative distribution functions (CDF) given that two samples are used to derive the CDFs and $F$ is the theoretical cumulative distribution of the distribution under study.

\section{Temperature indices}

Temperature indices employed in this study are shown in Table 2. These indices are generally given with respect to the exceedance of days or percentile thresholds. These indices were formulated following CLIVAR/GCOS/WMO workshop on indices and indicators for climate extremes. They have since been found useful by many scientists (e.g., Dietzsch et al. 2017; Panda et al. 2016) who have used them around the world in climate change studies.

The analytical approach embodied herein considers 30-year periods for the middle (2021-2050) and end (2071-2100) of the century. Anomalies are calculated with reference to a 1961-1990 baseline period. Calculation of anomalies was chosen over the use of absolute temperature values because in climate change science, temperature anomalies are more informative. For example, when a positive anomaly has been computed, it indicates that the observed temperature was warmer than the baseline. Conversely, when a negative anomaly has been computed, it indicates that the observed temperature was colder than the baseline. The approach of analysis utilized in this study was also successfully used in recent studies by Ongoma et al. (2018) over Equatorial East Africa and Tomozeiu et al. (2014) over Northern Italy.

\section{Results and discussion}

Results from this study have been displayed and discussed under 5 subsections, i.e., (1) The first section displays and discusses the performance of each model, (2) percentilebased indices: these are given and discussed as days with the warmest or coldest percentiles and they include: warm days $\left(\mathrm{TX}_{90 p}\right)$, warm nights $\left(\mathrm{TN}_{90 p}\right)$, cool days $\left(\mathrm{TX}_{10 p}\right)$ and cool nights $\left(\mathrm{TN}_{10 p}\right),(3)$ absolute indices: these are displayed and discussed in terms of the maximum and minimum of temperature values and they include: maximum of annual maximum temperature $\left(\mathrm{TX}_{x}\right)$, minimum of annual minimum temperature $\left(\mathrm{TN}_{n}\right)$, annual maximum of daily minimum temperature $\left(\mathrm{TN}_{x}\right)$, annual minimum of daily maximum temperature $\left(\mathrm{TX}_{n}\right)$, (4) duration indices: as the name implies, duration indices refer to timespan, i.e., excessiveness of given meteorological parameters (e.g., excessive warmth, coldness, wetness or dryness) over a prolonged period of time. The only duration-based index discussed in this study is WSDI due to its detrimental effects on ecosystems, health, agriculture, and water resources, (5) subsection 5 documents a discussion on the projections of potential changes in the impacts of the observed temperature increments.

\section{Model performance}

A statistical summary of the ability of models to simulate temperature over Zambia in comparison with CRU TS v4.01 data is shown in Table 3. These results indicate that 14 models are under-estimating CRU TS v4.01 and 4 are overestimating it. Generally, all models accurately mimic the trend of temperature over Zambia with only CESM-1-CAM5 being negatively correlated to CRU TS v4.01. 5 Models that scored $\leq 1{ }^{\circ} \mathrm{C}$ RMSE and bias were selected and included in

Table 2 Climate change indices used in this study

\begin{tabular}{|c|c|c|c|c|}
\hline Indices & Name & Calculation & Definition & Units \\
\hline \multicolumn{5}{|c|}{ Absolute indices } \\
\hline $\mathrm{TX}_{x}$ & $\operatorname{Max} T_{\max }$ & $\mathrm{TX}_{x_{k j}}=\max \left(\mathrm{TX}_{x_{k j}}\right)$ & Annual maximum value of daily maximum temperature & ${ }^{\circ} \mathrm{C}$ \\
\hline $\mathrm{TN}_{x}$ & $\operatorname{Max} T_{\min }$ & $\mathrm{TN}_{x_{k j}}=\max \left(\mathrm{TN}_{x_{k j}}\right)$ & Annual maximum value of daily minimum temperature & ${ }^{\circ} \mathrm{C}$ \\
\hline $\mathrm{TX}_{n}$ & $\operatorname{Min} T_{\max }$ & $\mathrm{TX}_{n_{k j}}=\min \left(\mathrm{TX}_{n_{k j}}\right)$ & Annual minimum value of daily maximum temperature & ${ }^{\circ} \mathrm{C}$ \\
\hline $\mathrm{TX}_{n}$ & $\operatorname{Min} T_{\min }$ & $\mathrm{TN}_{n_{k j}}=\min \left(\mathrm{TN}_{n_{k j}}\right)$ & Annual minimum value of daily minimum temperature & ${ }^{\circ} \mathrm{C}$ \\
\hline \multicolumn{5}{|c|}{ Percentile-based indices } \\
\hline $\mathrm{TN} 10_{p}$ & Cool nights & $\mathrm{TN}_{i j}<\mathrm{TN}_{\mathrm{in}} 10$ & Percentage of days when $\mathrm{TN}<10$ th percentile & $\%$ \\
\hline $\mathrm{TN} 10_{p}$ & Cool days & $\mathrm{TX}_{i j}<\mathrm{TX}_{i n} 10$ & Percentage of days when $\mathrm{TX}<10$ th percentile & $\%$ \\
\hline $\mathrm{TN} 90_{p}$ & Warm nights & $T N_{i j}>T N_{i n} 90$ & Percentage of days when $\mathrm{TN}>90$ th percentile & $\%$ \\
\hline$T X 90_{p}$ & Warm days & $\mathrm{TX}_{i j}>\mathrm{TX}_{i n} 90$ & Percentage of days when TX $>$ 90th percentile & $\%$ \\
\hline \multicolumn{5}{|c|}{ Duration index } \\
\hline WSDI & $\begin{array}{l}\text { Warm spell duration } \\
\text { indicator }\end{array}$ & $\mathrm{TX}_{i j}>\mathrm{TX}_{\mathrm{in}} 90$ & $\begin{array}{l}\text { Annual count of days with at least } 6 \text { consecutive days when } \\
\text { TX }>\text { 90th percentile of } 1961-1990\end{array}$ & Days \\
\hline
\end{tabular}


an ensemble. This was done under the assumption that models that show better retrospective simulations are likely to better simulate future climate (Lovino et al. 2018). The models that were selected include HaDGEM-2-ES of the Met Office Hadley Centre, MIROC-5 developed by the University of Tokyo, MRI-CGCM3 a product of the Meteorological Research Institute (Japan), CSIRO-MK360 developed by Commonwealth Scientific and Industrial Research Organization and GFDL-ESM-2G of the Geophysical Fluid Dynamics Laboratory, USA. It is important to note that although IPSL-CM-5A-LR of the Institut Pierre Simon Laplace had a Bias of $1.0^{\circ} \mathrm{C}$, it was not included in the ensemble because its RMSE was higher than the set $1.0^{\circ} \mathrm{C}$ threshold.

The resulting ensemble showed an improved correlation coefficient of 0.5 with both RMSE and Bias being less than $1{ }^{\circ} \mathrm{C}$. The 0.5 coefficient observed herein is lower than what has previously been reported in other areas, e.g., Argentina were coefficients as high as 0.9 were found (Lovino et al. 2018). This shows that generally, over Africa models do not perform as well as they do in other regions. Overall, the ensemble was found to be under-reading CRU TS v4.01.This under-reading was thought to be a result of the general performance of the input models because 3 out of the selected 5 had negative bias coefficients. Additionally, CMIP5 models tend to exhibit cool biases over Africa (McSweeney et al. 2015).

Table 3 Statistical summary of model performance

\begin{tabular}{lllll}
\hline Model & $\begin{array}{l}\text { Annual } \\
\text { mean temp }\end{array}$ & Correlation R & RMSE & Bias \\
\hline BCC-CSM-1-1M & 23.2 & 0.4 & 1.4 & 1.3 \\
BNU-ESM & 20.7 & 0.3 & 1.2 & -1.1 \\
CCSM4 & 20.2 & 0.4 & 1.6 & -1.6 \\
HaDGEM-2-ES & 21.1 & 0.1 & 0.9 & -0.7 \\
CNRM-CM5 & 19.8 & 0.3 & 2.1 & -2.0 \\
IPSL-CM-5A-LR & 20.8 & 0.3 & 1.1 & -1.0 \\
MIROC-5 & 21.9 & 0.1 & 0.4 & 0.03 \\
MPI-ESM-LR & 20.3 & 0.3 & 1.5 & -1.4 \\
MPI-ESM-MR & 20.5 & 0.1 & 1.4 & -1.3 \\
MRI-CGCM3 & 21.2 & 0.3 & 0.7 & -0.6 \\
NOR-ESM-1-ME & 19.2 & 0.4 & 2.6 & -2.6 \\
ENSEMBLE & 20.9 & 0.5 & 0.9 & -0.8 \\
CSIRO-MK360 & 22.3 & 0.2 & 0.5 & 0.4 \\
EC-EARTH & 19.2 & 0.3 & 2.6 & -2.6 \\
FGOALS-G2 & 20.2 & 0.4 & 1.6 & -1.6 \\
FIO-ESM & 20.6 & 0.5 & 1.2 & -1.2 \\
GFDL-ESM-2G & 20.9 & 0.1 & 1.0 & -0.9 \\
GISS-E2-H & 23.8 & 0.2 & 2.1 & 2.0 \\
CESM-1-CAM5 & 19.6 & -0.1 & 2.2 & -2.1 \\
CRU & 21.8 & 1 & 0 & 0 \\
\hline
\end{tabular}

Ensemble and CRU are highlighted in italic

\section{Changes of percentile-based temperature indices}

Figure 2 shows patterns of change over Zambia, in percentage of days, when daily maximum temperature is above the 90th percentile (TX90p) and percentage of days when daily minimum temperature is also above the 90th percentile (TN90p). Two key findings standout from these results (1) relative to the baseline period (1961-1990), there is a positive shift in all cases; (2) there are higher increments over the northern half of the country, and they decrease southwards in all cases.

It is important to note that datasets used in this study were constructed to account for the rate of exceedance (\%). In this case, much of southern Zambia is projected to experience $\sim 30 \%$ increment in TX90p while the northern half will experience $\sim 40 \%$ under RCP4.5 during the middle of the century (2021-2150). If the business-as-usual trajectory (RCP8.5) is followed, an intensification of TX90p is observed with $\sim 40 \%$ in the southern half of the country and $\sim 50 \%$ in the northern half. These projections are observed to almost double towards the end of the century. Increments embodied herein are lower than what has been projected in other parts of Africa. For example, increments as large as 90\%, in Tx90p are projected over sub equatorial Africa, in particular, over the gulf of Guinea, Central African Republic, and South Sudan (Dosio 2016).

The projected increase in warm nights (TN90p) is more over Luapula and Northwestern province while the lowest is observed over the Livingstone/Magoye region. Higher increment over most parts of northern Zambia can be attributed to their closeness to the equatorial region as compared to the southern half. Topography is equally a major modifier of Zambia's temperature (Reason 2016).

Cool days (TX10p) and nights (TN10p) exhibit a negative shift over the whole country (Fig. 3). This implies an increment in the distribution of daily minimum temperatures and overall significant warming (Alexander et al. 2006). A downward gradient from the north to the south of the country is again evident with higher departures from the normal being observed over much of the northern part of the country and decreasing southwards. Evidence of the lowest departure from the normal is mainly seen in the eastern part of the country especially south of the Luangwa valley. Conclusively, a noticeable decrease in cool days and nights is projected especially over Northern and Northwestern Zambia compared to the south and eastern parts of the country.

The results found in this study complement the findings of Alexander et al. (2006) who estimated that $>70 \%$ of the global landmass will experience a significant decrease in the annual occurrence of cold nights while at the same time, a significant increase in warm nights is to be expected.

Temporal changes in cool (TX10p) and warm (TX90p) days are shown in Fig. 4a and b. A positive (negative) 
(a) TX90p RCP4.5 Mid

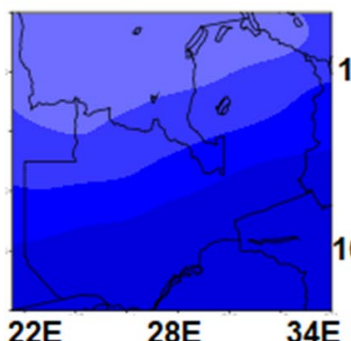

$22 \mathrm{E}$ (b) TX90p RCP4.5 End

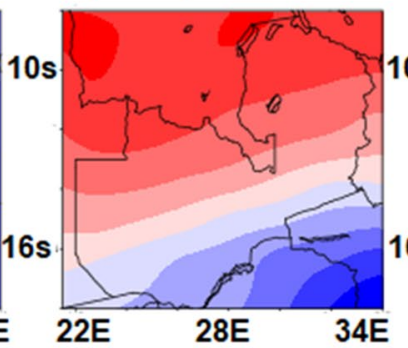

(e) TN90p RCP4.5 Mid

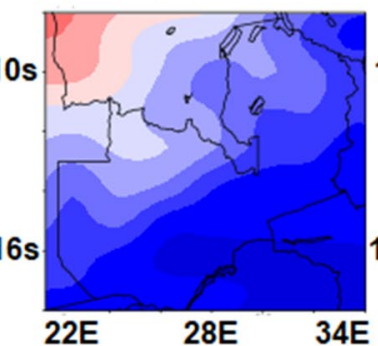

(f) TN90p RCP4.5 End

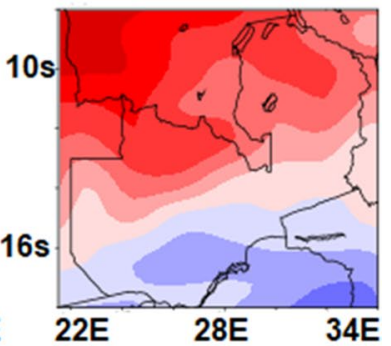

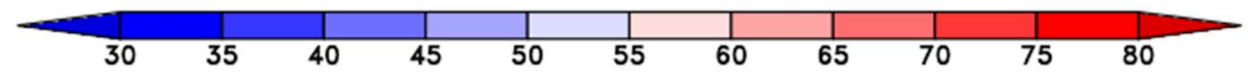

(c) TX90p RCP8.5 Mid

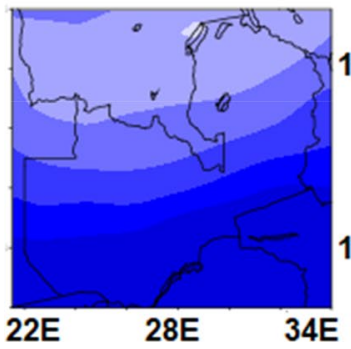

(d) TX90p RCP8.5 End

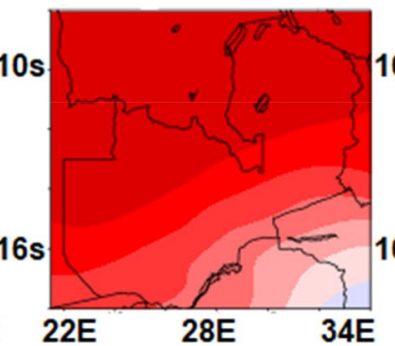

(g) TN90p RCP8.5 Mid

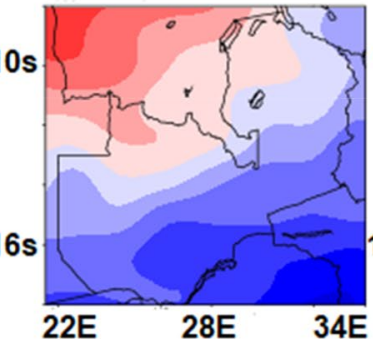

(h) TN90p RCP8.5 End

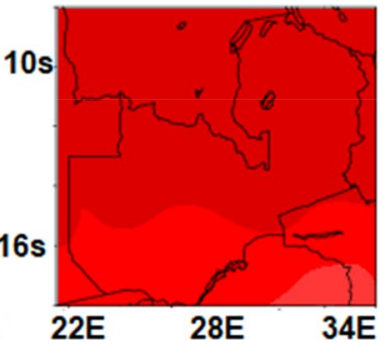

Fig. 2 Spatial changes of: a, c warm days for the period 2021-2050, b, d warm days for the period 2071-2100, e, $\mathbf{g}$ warm nights for the period 2021-2050, f, h warm nights for the period 2071-2100. Top panel shows simulations using RCP4.5 while the bottom panel shows $\mathrm{RCP} 8.5$ relative to the baseline period

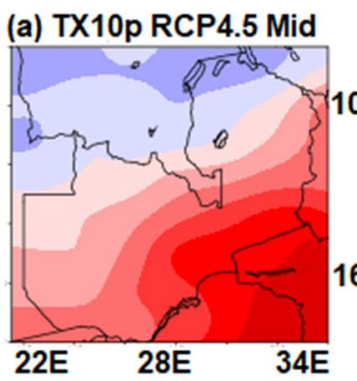

(b) TX10p RCP4.5 End

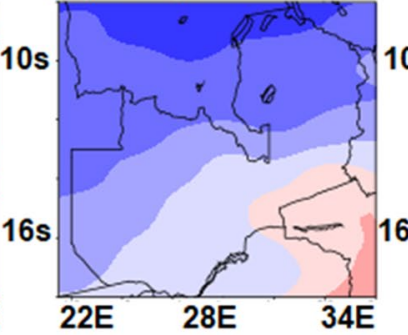

(e) TN10p RCP4.5 Mid

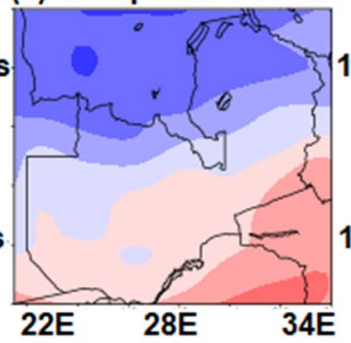

(f) TN10p RCP4.5 End

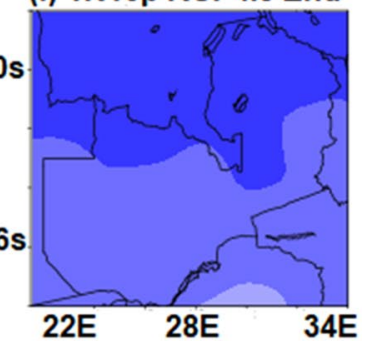

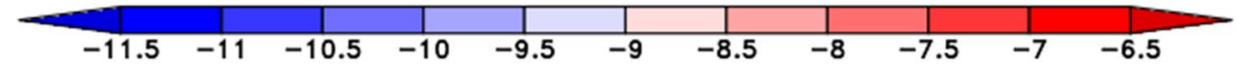

(c) TX10p RCP8.5 Mid

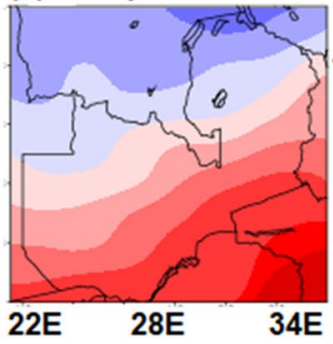

(d) TX10p RCP8.5 End

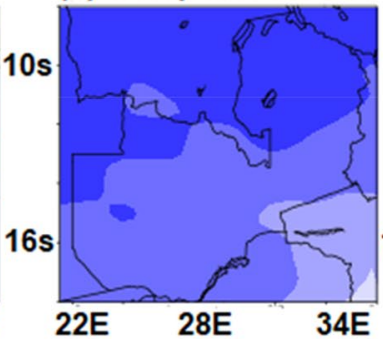

Fig. 3 Spatial changes of: a, c cool days for the period 2021-2050 b, d cool days for the period 2071-2100, e, g cool nights for the period 2021-2050, f, h cool nights for the period 2071-2100. Top (g) TN10p RCP8.5 Mid

(h) TN10p RCP8.5 End
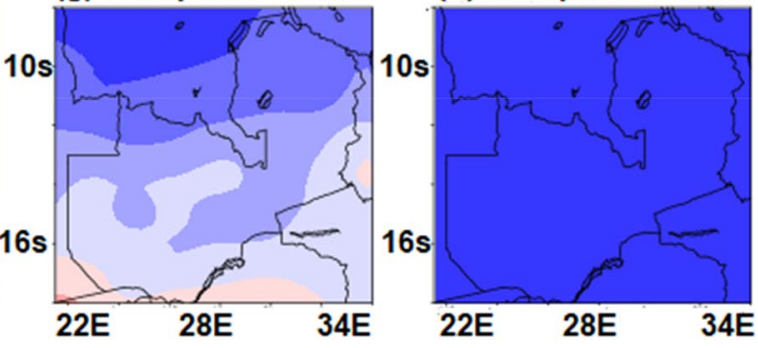

panel shows simulations using RCP4.5 while the bottom panel shows RCP8.5 relative to the baseline period 
increment in warm (cool) days is evident around the $80 \mathrm{~s}$ and intensifies just before the mid of the century. The rate of exceedance of cool days drops steadily from $\sim 10$ to $0 \%$ by the end of the century implying nonexistence of cool days with respect to the baseline period by 2100 . This reconfirms the results found in the spatial analyses (Fig. 3) which showed a decrease in cool days and nights. Under RCP4.5, the rate of exceedance of warm days (TX90p) range from $10 \%$ from the beginning of the study period to $70 \%$ at the end of the century and this intensifies under RCP8.5 reaching an exceedance of $\sim 90 \%$ by 2100 .

\section{Changes of absolute temperature indices}

Apart from the Chipata, Luangwa, Petauke and surrounding areas, absolute temperature changes (Fig. 5) indicate an almost uniform increment of annual maximum value of daily maximum temperature $\left(\mathrm{TX}_{x}\right)$ under RCP4.5 for the period 2021-2050. The increment averages $\sim 2{ }^{\circ} \mathrm{C}$ under RCP4.5 and rises to $\sim 3.5^{\circ} \mathrm{C}$ under RCP8.5. In general, RCP8.5 shows more spatial variability than RCP4.5. A positive shift in $\mathrm{TN}_{n}$ is also projected during the period 2021-2050 to exhibit an increment of $\sim 2{ }^{\circ} \mathrm{C}$ (RCP4.5) and $\sim 3{ }^{\circ} \mathrm{C}$ (RCP8.5). Noticeably, in all cases, the projections over Zambia double by the end of the 21 st century with, as expected, the highest values being observed under the business-as-usual concentration pathway. The values reach as high as $6.5^{\circ} \mathrm{C}$ for both $\mathrm{TXx}$ and $\mathrm{TN}_{n}$ in Western and Southern Provinces.

By 2050, Max $T_{\min }\left(\mathrm{TN}_{x}\right)$ is projected under RCP4.5 to be highest around Northern Province and parts of Eastern Province (Fig. 6a). In general, the projections are up to $2.5^{\circ} \mathrm{C}$ across the country. This threshold is however crossed under RCP8.5 with both annual maximum value of daily minimum temperature $\left(\mathrm{TN}_{x}\right)$ and annual minimum value of daily maximum temperature $\left(\mathrm{TX}_{n}\right)$ being projected to have a temperature increment of more than $5.5^{\circ} \mathrm{C}$ over the whole country (Fig. $6 \mathrm{~d}, \mathrm{~h}$ ).

Figure 7 shows changes in absolute temperature indices. A positive shift in temperature is noted in all instances intensifying with an increase in radiative forcing and time. From 2021 the simulations between RCP4.5 and RCP8.5 do not exhibit major differences but after the mid of the century (2050), the differences become more pronounced with RCP8.5 projecting higher increments as expected. A
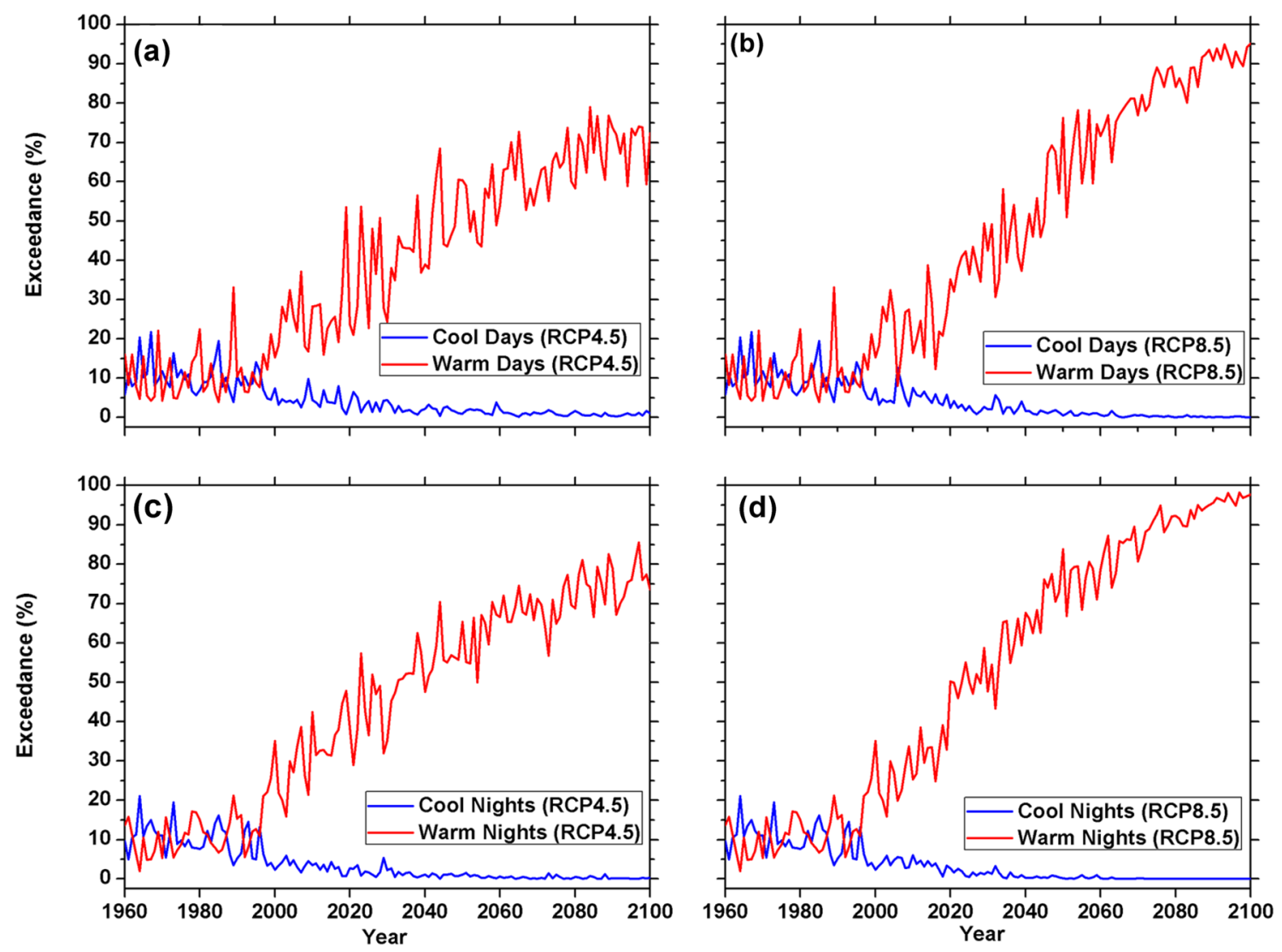

Fig. 4 Temporally averaged changes of: $\mathbf{a}, \mathbf{b}$ cool and warm days; $\mathbf{c}, \mathbf{d}$ cool and warm nights. The left panel shows simulations from RCP4.5 and the right panel shows RCP8.5 
(a) TXX RCP4.5 Mid

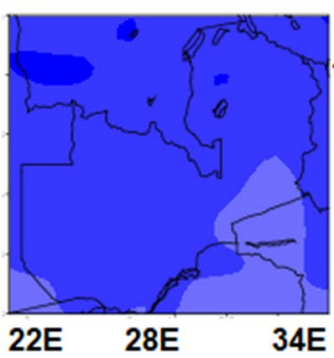

(b) TXX RCP4.5 End

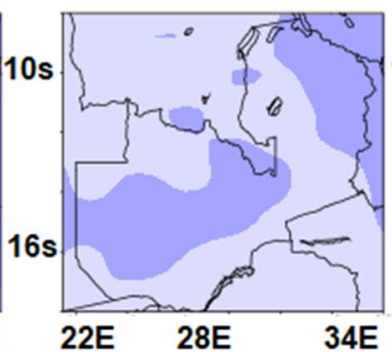

(e) TNn RCP4.5 Mid

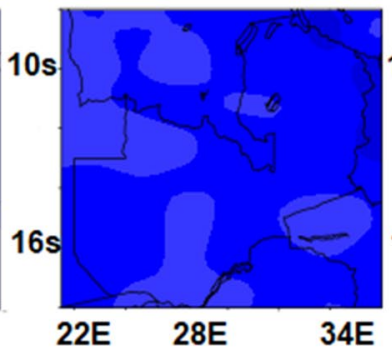

(f) TNn RCP4.5 End

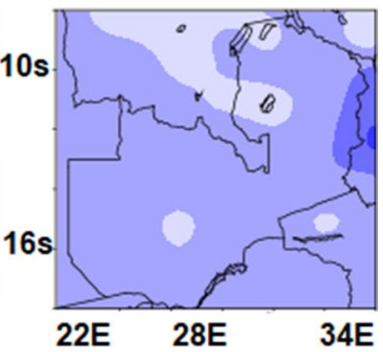

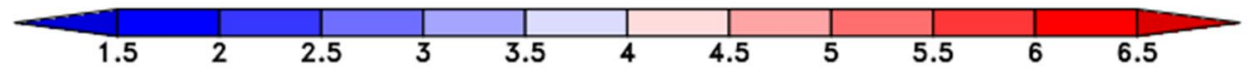

(c) TXX RCP8.5 Mid

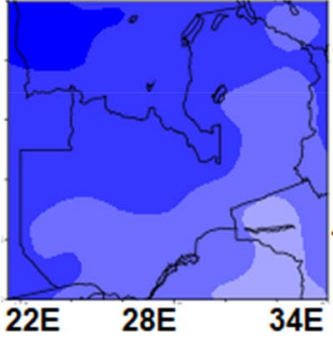

(d) TXX RCP8.5 End

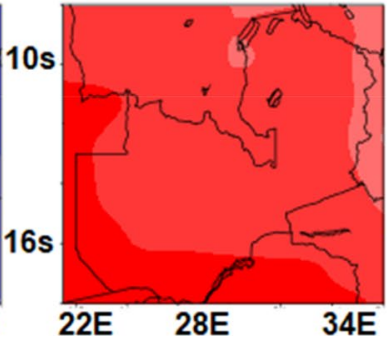

Fig. 5 Spatial changes of: a, c Max $T_{\max }$ (TXx) for the period 20212050, b, d Max $T_{\max }(\mathrm{TXx})$ for the period 2071-2100, e, g Min $T_{\min }$ $\left(\mathrm{TN}_{n}\right)$ for the period 2021-2050, f, h Min $T_{\min }\left(\mathrm{TN}_{n}\right)$ for the period (g) TNn RCP8.5 Mid

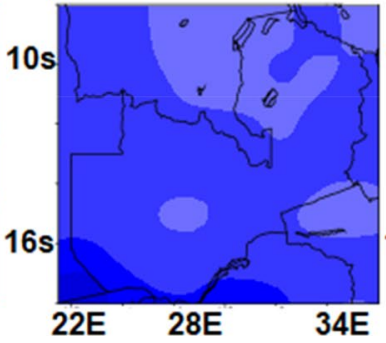

(h) TNn RCP8.5 End

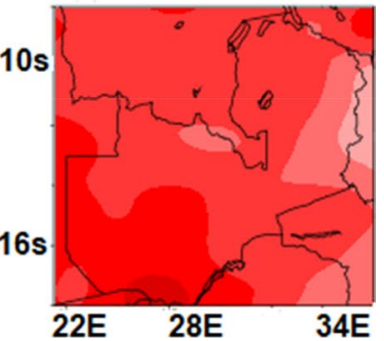

2071-2100. Top panel shows simulations using RCP4.5 while the bottom panel shows RCP8.5 relative to the baseline period

(e) TXn RCP4.5 Mid

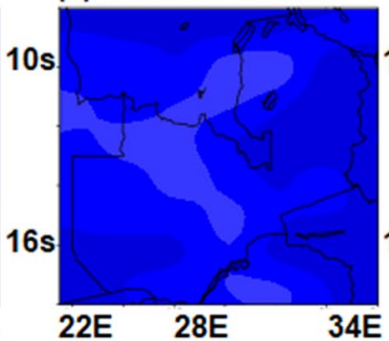

(f) TXn RCP4.5 End

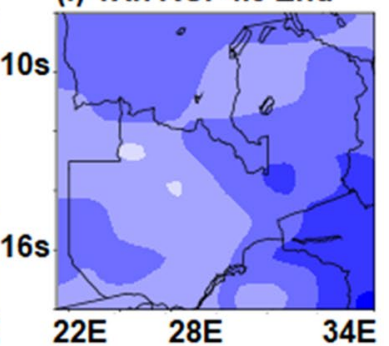

(a) TNx RCP4.5 Mid

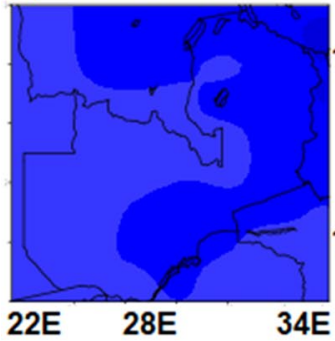

(b) TNx RCP4.5 End

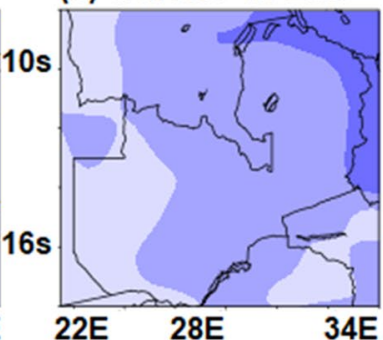

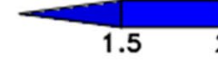

(c) TNx RCP8.5 Mid

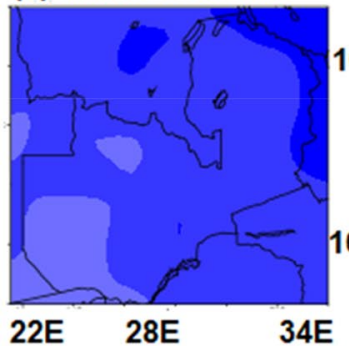

(d) TNx RCP8.5 End

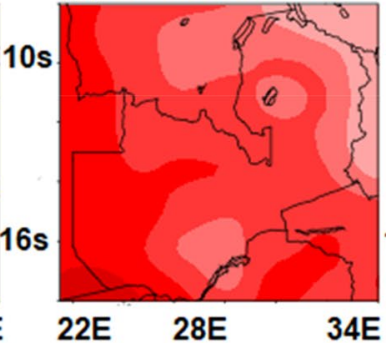

Fig. 6 Spatial changes of: a, c Max $T_{\min }\left(\mathrm{TN}_{x}\right)$ for the period 20212050, b, d Max $T_{\min }\left(\mathrm{TN}_{x}\right)$ for the period 2071-2100, e, g Min $T_{\max }$ $\left(\mathrm{TX}_{n}\right)$ for the period 2021-2050, $\mathbf{f}, \mathbf{h}$ Min $T_{\max }\left(\mathrm{TX}_{n}\right)$ for the period (g) TXn RCP8.5 Mid

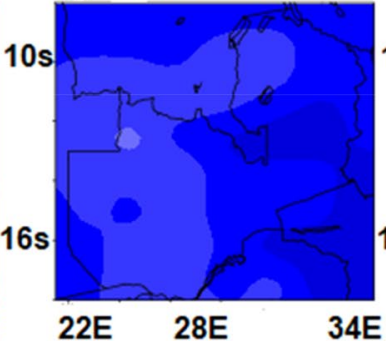

(h) TXn RCP8.5 End

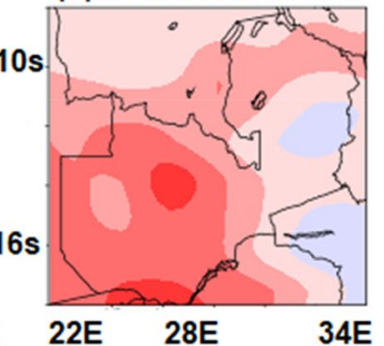

2071-2100. Top panel shows simulations using RCP4.5 while the bottom panel shows RCP8.5 relative to the baseline period 
summary of the magnitude of increments as computed by the Sen's slope estimator is presented in Table 4 below.

\section{Changes of duration indices}

Annual trends of warm spell duration indicator (WSDI) are projected to increase under both RCP4.5 and RCP8.5 (Fig. 8) relative to the 1961-1990 baseline period. The observed increase in WSDI can be attributed to the simulated temperature increments. These findings are in line with the findings of Ongoma et al. (2018) who observed an increase in WSDI over Equatorial East Africa and attributed it to temperature increments and low tropical temperature variations. While substantial spatial variability is observed in this study, Northern Province is projected to have more intense WSDI compared to the rest of the country. These changes will potentially exert adverse environmental and economic effects as discussed in the introduction. Again, under RCP 8.5, intensification of WSDI is observed especially towards the end of the century.

Probability density functions (PDF) were used to investigate the temporal shifts of WSDI over Zambia. These results are given in Fig. 9. Here, the positive shifts in the PDFs
Table 4 Annual Sen's slope of the projected temperatures $\left({ }^{\circ} \mathrm{C}\right)$ over Zambia based on CMIP5 ensemble mean data for the period 2006-2100

\begin{tabular}{lll}
\hline Variable & \multicolumn{2}{l}{ Scenario } \\
\cline { 2 - 3 } & RCP4.5 & RCP8.5 \\
\hline $\mathrm{TXx}$ & 0.65 & 0.83 \\
$\mathrm{TN}_{n}$ & 0.45 & 0.67 \\
$\mathrm{TN}_{x}$ & 0.75 & 0.88 \\
$\mathrm{TX}_{n}$ & 0.54 & 0.72 \\
\hline
\end{tabular}

indicate an increment in the annual WSDI values. Additionally, an elongation of the tails of the PDFs towards higher values shows an intensification of WSDI. Generally, WSDI is projected, under RCP4.5 and RCP8.5 to increase with increase in radiative forcing and time. Many scientists (e.g., Ongoma et al. 2018; Fallmann et al. 2017) have used PDFs in similar studies.

\section{Potential future impacts}

A fuller understanding of potential future impacts of extreme temperature in view of the results presented above requires a thorough examination of how temperature modulates other sectors. Table 5 displays projected potential
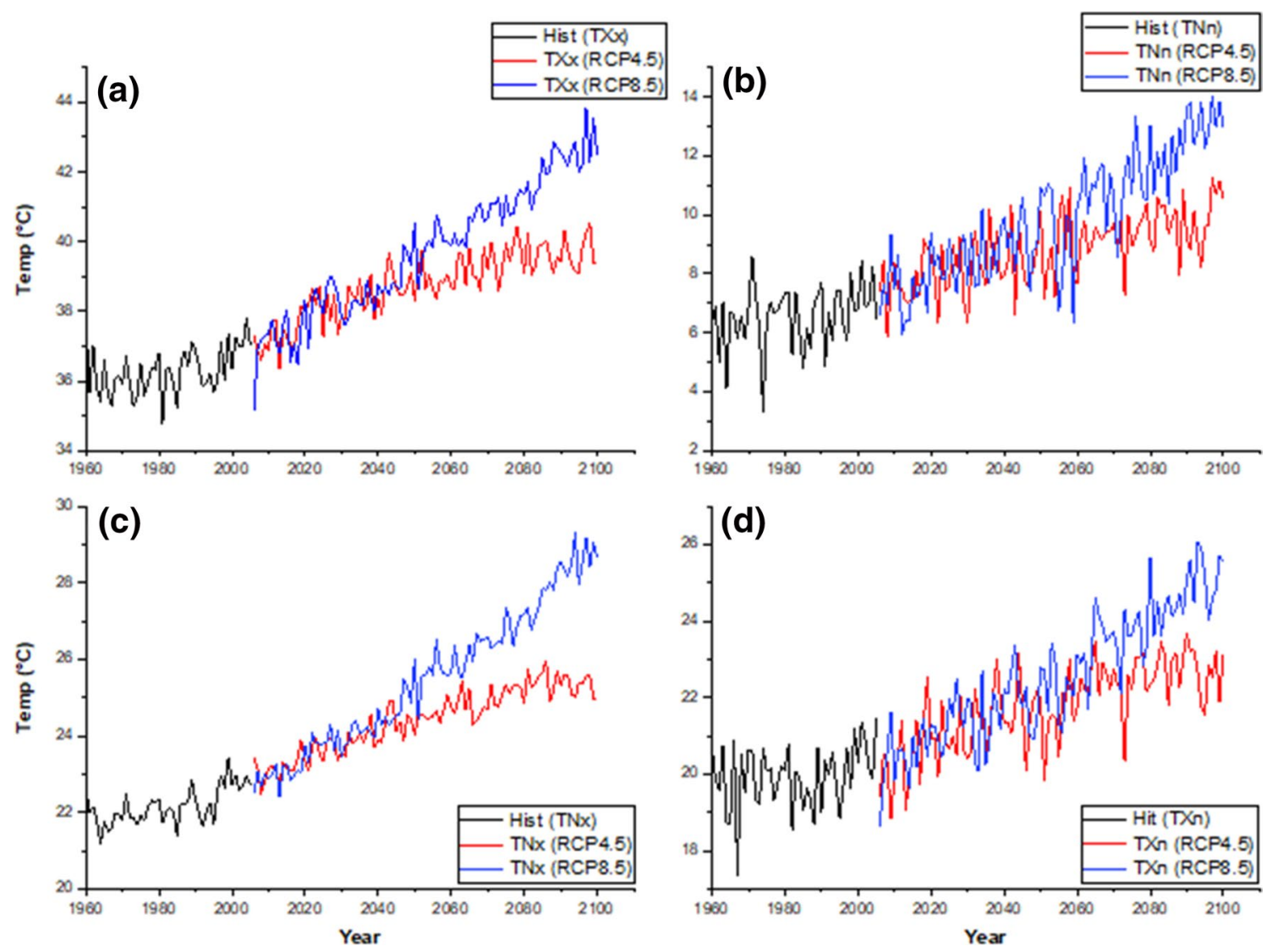

Fig. 7 Temporally averaged changes of a Max $T_{\max }\left(\mathrm{TX}_{x}\right)$, b Min $T_{\min }\left(\mathrm{TN}_{n}\right)$, c Max $T_{\min }\left(\mathrm{TN}_{x}\right), \mathbf{d} \operatorname{Min} T_{\max }\left(\mathrm{TX}_{n}\right)$. Black color shows historical, red shows simulations under RCP4.5 and blue RCP 8.5 
(a) WSDI RCP 4.5 Mid

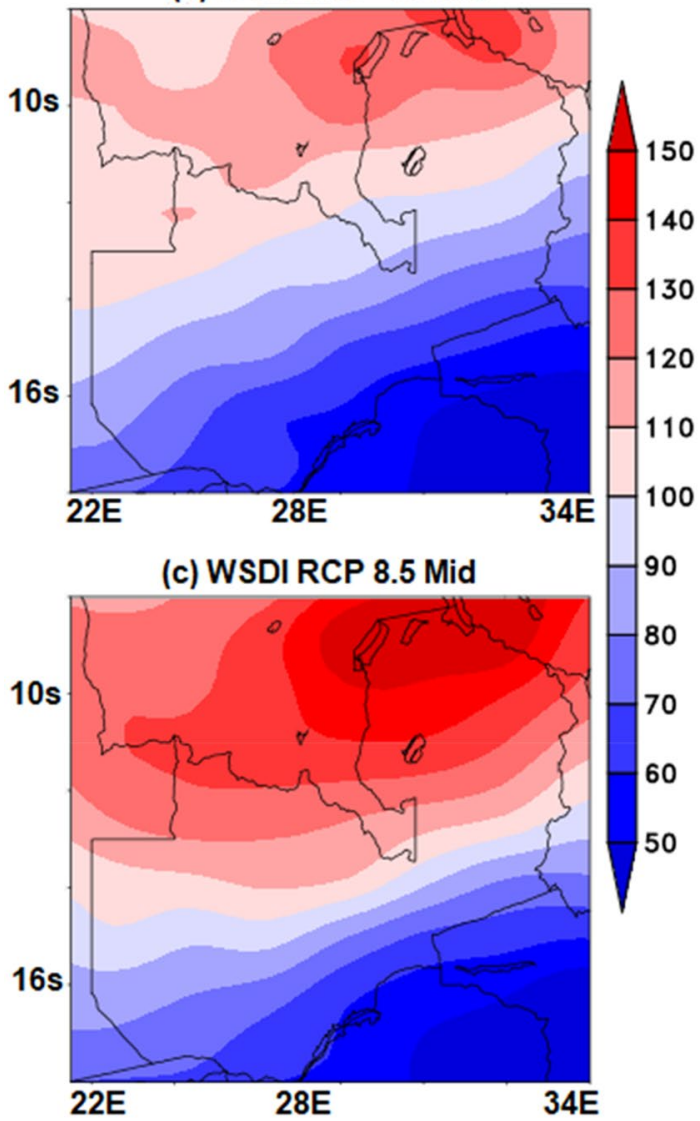

(b) WSDI RCP 4.5 End

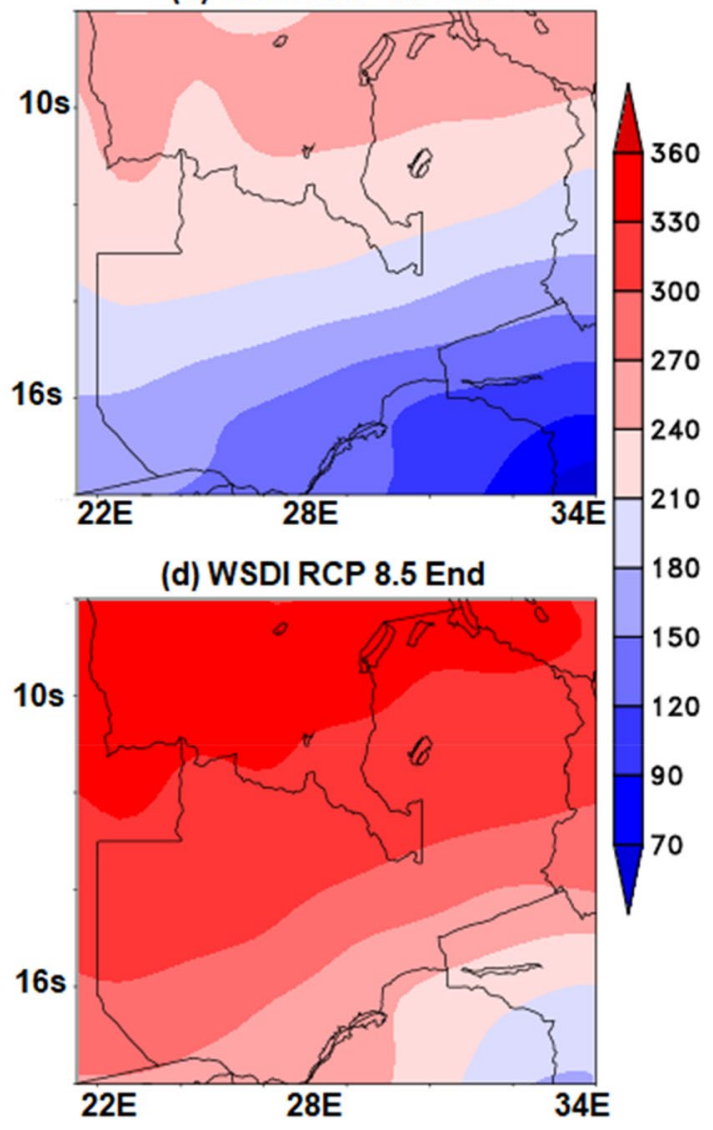

Fig. 8 Trends of WSDI for 2021-2050 (left panel) and 2071-2100 (right panel). The top panel shows projections under RCP4.5 while the bottom panel shows RCP8.5. All projections are given relative to the 1961-1990 baseline period

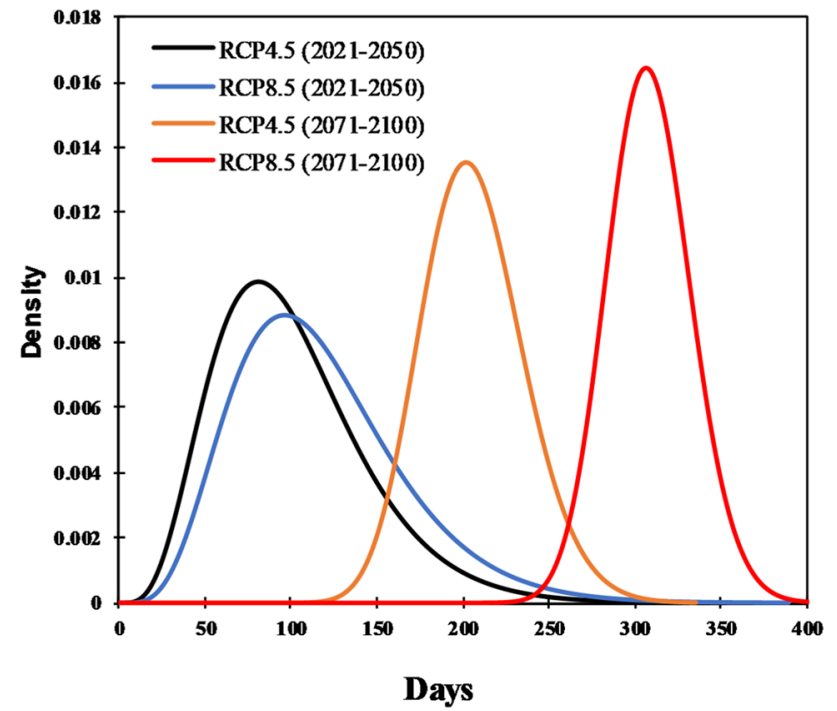

Fig. 9 Density functions of WSDI for RCP4.5 (black; 2021-2050), RCP8.5 (blue; 2021 -2050), RCP4.5 (orange; 2071-2100), RCP8.5 (red; 2071-2100). All projections are given relative to the 1961-1990 baseline period changes in future climate impacts based on the current understanding of the interlinkages between temperature and other sectors.

Regarding the projected 30-65\% (i.e., combined RCP4.5 and RCP8.5) increase in warm days and nights relative to the baseline period, this will potentially slow down tree growth in the country's miombo woodlands, a conservation hotspot crucial for the maintenance of a wide array of ecosystem products and services (Dewees et al. 2010; Ryan et al. 2016), and sustenance of their rich terrestrial biodiversity (Campbell 1996). The argument here is that the rise in temperature will likely lead to a reduction in soil moisture thereby negatively affecting tree growth especially because interactions between temperature and rainfall have previously been found to explain 60-98\% of tree growth variance in Zambia (Chidumayo 2005). Ryan et al. (2016) also computed that changes in the climate are likely to reduce plant available water across the miombo woodlands which will not only reduce tree growth rates but increase drought-related mortality. Further, since the kinetic energy of water molecules is inherently proportional to its temperature (Monteith 2007), higher evaporation rates are to be expected with an increase 
Table 5 Projected extreme temperature and potential future impacts in Zambia

\begin{tabular}{ll}
\hline Index & Future scenario (By 2050) \\
\hline Percentile-based temperature indices & $30-40 \%$ increase in warm days (TX90p) under \\
RCP 4.5 and $40-50 \%$ under RCP 8.5 \\
$30-65 \%$ increase in warm nights (TN90p) under \\
RCP4.5 and 40-75\% under RCP 8.5 \\
$6.5-9 \%$ decrease in cool days (TX10p) under \\
RCP4.5 and -7-9.5\% under RCP 8.5 \\
$8.5-10 \%$ decrease in cool nights (TN10p) under \\
RCP 4.5 and $9-10 \%$ under RCP 8.5
\end{tabular}

Potential future impacts

Interactions between temperature and rainfall have previously been found to explain $60-98 \%$ of tree growth variance in Zambia (Chidumayo 2005). Observed temperature increments are thus, likely to lead to a reduction in soil moisture. This will potentially slow down tree growth in the country's miombo woodlands, an ecosystem crucial for the maintenance of a wide array of ecosystem products and services (Dewees et al. 2010; Ryan et al. 2016), and sustenance of their rich terrestrial biodiversity (Campbell 1996)

The kinetic energy of water molecules is inherently proportional to its temperature (Monteith 2007); therefore, higher evaporation rates are to be expected at high temperatures. This will reduce plant yields and potentially lead to significant land use changes (Ryan et al. 2016)

Absolute temperature indices

Duration indices

\author{
$\sim 2{ }^{\circ} \mathrm{C}$ increase in Max $T_{\max }\left(\mathrm{TX}_{x}\right)$ under RCP4.5 \\ and $3.5^{\circ} \mathrm{C}$ under RCP8.5; \\ $\sim 2{ }^{\circ} \mathrm{C}$ increase in Min $T_{\text {min }}\left(\mathrm{TN}_{n}\right)$ under RCP4.5 \\ and $\sim 3{ }^{\circ} \mathrm{C}$ under RCP8.5 \\ $\sim 2{ }^{\circ} \mathrm{C}$ increase in Max $T_{\max }\left(\mathrm{TN}_{x}\right)$ under RCP 4.5 \\ and $\sim 3{ }^{\circ} \mathrm{C}$ under RCP 8.5 \\ $\sim 1.5-2{ }^{\circ} \mathrm{C}$ increase in Min $T_{\max }\left(\mathrm{TX}_{n}\right)$ under RCP \\ 4.5 and $\sim 1.5-3{ }^{\circ} \mathrm{C}$ under RCP 8.5
}

$50-120$ days increase in WSDI under RCP 4.5 and 70-150 days under RCP 8.5
Increase in maximum and minimum temperatures coupled with projected rainfall decrease (Libanda and Chilekana 2018) are highly likely to lead to a strain on Zambia's water resources thereby exacerbating the already unstable supply of hydropower electricity (Hill 2016)

Warm spells lead to agricultural failure (Bhat 2006). Northern Province is projected to have more intense WSDI compared to the rest of the country; this is likely to disrupt the location of rural settlements in the area with migrations of both Arable and Pastoral farmers away from the region being possible. in temperature. This will reduce plant yields and potentially lead to significant land use changes (Ryan et al. 2016).

Increase in maximum and minimum temperatures coupled with projected rainfall decrease (Libanda and Chilekana 2018) are highly likely to lead to a strain on Zambia's water resources thereby exacerbating the supply of hydropower electricity. It is important to note that Zambia sources $\geq 95 \%$ of its power needs from hydroelectricity and in recent years, whenever the country experienced meteorological drought, Lake Kariba has had dangerously low water levels leading to critical reductions in power generation and as a consequence adversely affecting all socio-economic activities for both Zambia and neighbouring Zimbabwe (Hill 2016).

Regarding the projected increase in WSDI, it is well documented that warm spells lead to agricultural failure (Bhat 2006). Northern Province is projected to have more intense WSDI compared to the rest of the country; this is likely to disrupt the location of rural settlements in the area with migrations of both Arable and Pastoral farmers away from the region being possible. It is important to note that most farmers in Zambia are small-scale, a group known to be most vulnerable to changes in the climate due to low coping capacity. Although in recent years there has been a surge in commercial farming ventures, only $2 \%$ of the total farmer population are large-scale (MAFF 1992).

Prolonged warm spells have also been known to pose a threat to human health and sometimes leading to death such as was the case in north-eastern Nigeria when temperatures $>50{ }^{\circ} \mathrm{C}$ were experienced in 2002 (Dosio 2016).

In view of the foregoing, Zambia's approach to climate change adaptation and mitigation will need to encompass all sectors inter alia ecosystems, agriculture, water resources, and health.

\section{Conclusion}

Interrogating extreme climate variability and change at the local level paves way to understanding the impacts of extremes on climate-sensitive sectors and consequently provides useful information for adaptive and mitigative processes. Although this study focuses on extreme temperature, the findings have a bearing on rainfall and the entire hydrological cycle. 
The following conclusions can be drawn from the present study: warm days and nights are projected to become warmer while cool days and nights are projected to become non-existent by 2100 . Towards the end of the twenty-first century, intensification of temperature in all its forms is noted to double that of the 2021-2050 period. Much of southern Zambia is projected to experience up to $\sim 30 \%$ increment in TX90p while the northern half will experience up to $~ 40 \%$ under RCP 4.5 during the middle of the century (2021-2050). If the business-as-usual trajectory (RCP8.5) is followed, an intensification of TX90p is observed with up to $\sim 40 \%$ in the southern half of the country and up to $~ 50 \%$ in the northern half. RCP8.5 almost always exhibits a doubling of RCP4.5 because it uses the assumption that human population will increase, growth rate of income and technological advancement will be low, consequently, greenhouse gas emissions will be high (Riahi et al. 2011). The projected increase in warm nights (TN90p) is more over Luapula and Northwestern province while the lowest is observed over the Livingstone/Magoye region. Under RCP8.5 both annual maximum value of daily minimum temperature $\left(\mathrm{TN}_{x}\right)$ and annual minimum value of daily maximum temperature $\left(\mathrm{TX}_{n}\right)$ are projected to have a temperature increment of more than $5.5^{\circ} \mathrm{C}$ over the whole country. Annual trends of warm spell duration indicator (WSDI) are projected to increase under both RCP4.5 and RCP8.5.

Taken together, these findings suggest a role for strategic planning in promoting alternative solutions in Zambia. For example, considering that Lake Kariba currently suffers critical low water levels to sustainably supply Zambia's energy needs (Hill 2016), projections embodied herein can inform decision-making processes in water resources management. This work also fills research gaps inherent in the generalities usually made by global or continental climate projection studies.

Acknowledgements Canadian Centre for Climate Modelling and Analysis (CCCMA), Climatic Research Unit of the University of East Anglia and the Joint Institute for the Study of the Atmosphere and Oceans (JISAO) are acknowledged for the datasets used in this study. The Author carried out this work while being supported by a doctoral scholarship funded by the University of Edinburgh; The University is hereby acknowledged.

\section{Compliance with ethical standards}

Conflict of interest The author declares that there is no conflict of interest.

Open Access This article is licensed under a Creative Commons Attribution 4.0 International License, which permits use, sharing, adaptation, distribution and reproduction in any medium or format, as long as you give appropriate credit to the original author(s) and the source, provide a link to the Creative Commons licence, and indicate if changes were made. The images or other third party material in this article are included in the article's Creative Commons licence, unless indicated otherwise in a credit line to the material. If material is not included in the article's Creative Commons licence and your intended use is not permitted by statutory regulation or exceeds the permitted use, you will need to obtain permission directly from the copyright holder. To view a copy of this licence, visit http://creativecommons.org/licenses/by/4.0/.

\section{References}

Alexander L, Zhang X, Peterson T, Caesar J, Gleason B, Klein Tank A, Haylock M, Collins D, Trewin B, Rahimzadeh F, Tagipour A, Rupa Kumar K, Revadekar J, Griffiths G, Vincent L, Stephenson D, Burn J, Aguilar E, Brunet M, Taylor M, New M, Zhai P, Rusticucci M, Vazquez-Aguirre J (2006) Global observed changes in daily climate extremes of temperature and precipitation. $\mathrm{J}$ Geophys Res 111(D5):D05109

Bhat GS (2006) The Indian drought of 2002-a sub-seasonal phenomenon? Meteorol Soc 132:2583-2602. https://doi.org/10.1256/ qj.05.13

Brander KM (2007) Global fish production and climate change. Proc Natl Acad Sci USA 104:19709-19714. https://doi.org/10.1073/ pnas.0702059104

Campbell BM (1996) The Miombo in transition: woodlands and welfare in Africa. Forestry 72

Chaudhury M, Ajayi OC, Hellin J, Neufeldt H (2011) Climate change adaptation and social protection in agroforestry systems: enhancing adaptive capacity and minimizing risk of drought in Zambia and Honduras. Documento de trabajo. https://doi. org/10.5716/WP11269.PDF

Chidumayo EN (2005) Effects of climate on the growth of exotic and indigenous trees in central Zambia. J Biogeogr 32(1):111-120. https://doi.org/10.1111/j.1365-2699.2004.01130.x

Dale V, Joyce L, Mcnulty S, Neilson R, Ayres M, Flannigan M, Wotton B (2001) Climate change and forest disturbances: climate change can affect forests by altering the frequency, intensity, duration, and timing of fire, drought, introduced species, insect and pathogen outbreaks, hurricanes, windstorms, ice storms, or landslides. BioScience 51:723-734. doi.org/https://doi. org/10.1641/0006-3568(2001)051\%5b0723:ccafd\%5d2.0.co;2

Daw T, Adger W, Brown K, Badjeck M (2009) Climate change and capture fisheries: potential impacts, adaptation and mitigation. Climate change implications for fisheries and aquaculture. https://doi.org/FAO Fisheries and Aquaculture Technical paper No. 530

Dewees PA, Campbell BM, Katerere Y, Sitoe A, Cunningham AB, Angelsen A, Wunder S (2010) Managing the Miombo woodlands of Southern Africa: policies, incentives and options for the rural poor. J Nat Resour Policy Res 2(1):57-73. https://doi. org/10.1080/19390450903350846

Diallo I, Sylla MB, Giorgi F, Gaye AT, Camara M (2012) Multimodel GCM-RCM ensemble-based projections of temperature and precipitation over West Africa for the Early 21 st Century. Int J Geophys. https://doi.org/10.1155/2012/972896

Dietzsch F, Andersson A, Ziese M, Schröder M, Raykova K, Schamm K, Becker A (2017) A global ETCCDI-based precipitation climatology from satellite and rain gauge measurements. Climate 5:9. https://doi.org/10.3390/cli5010009

Dosio A (2016) Projection of temperature and heat waves for Africa with an ensemble of CORDEX regional climate models. Clim Dyn 49(1-2):493-519

Dosio A, Panitz H (2016) Climate change projections for CORDEX-Africa with COSMO-CLM regional climate model and differences with the driving global climate models. Clim Dyn 46(5-6):1599-1625 
Easterling DR, Meehl GA, Parmesan C, Changnon SA, Karl TR, Mearns LO (2000) Climate extremes: observations, modeling, and impacts. Science 289:2068-2074. https://doi.org/10.1126/ science.289.5487.2068

Falamarzi Y, Palizdan N, Huang YF, Lee TS (2014) Estimating evapotranspiration from temperature and wind speed data using artificial and wavelet neural networks (WNNs). Agric Water Manag 140:26-36. https://doi.org/10.1016/j.agwat.2014.03.014

Fallmann J, Wagner S, Emeis S (2017) High resolution climate projections to assess the future vulnerability of European urban areas to climatological extreme events. Theoret Appl Climatol 127:667683. https://doi.org/10.1007/s00704-015-1658-9

Fuss S (2010) A perspective paper on forestry carbon sequestration as a response to climate change. Copenhagen: Copenhagen Consensus Centre. Retrieved from www.copenhagenconsensus. com. Accessed 24 Dec 2017

Gerald AM, Warren M, Washington WDC, Julie M, Arblaster A, Hu LEB, Warren G, Strand HT (2005) How much more global warming and sea level rise? Science 307:1766-1769. https:// doi.org/10.1126/science. 1103934

Hachigonta S, Reason CJC (2006) Interannual variability in dry and wet spell characteristics over Zambia. Clim Res 32(1):49-62. https://doi.org/10.3354/cr032049

Harris I, Jones PD, Osborn TJ, Lister DH (2014) Updated high-resolution grids of monthly climatic observations- the CRU TS3.10 dataset. Int J Climatol 34:623-642. https://doi.org/10.1002/ joc. 3711

Hatfield JL, Prueger JH (2015) Temperature extremes: Effect on plant growth and development. Weather Clim Extremes 10:410. https://doi.org/10.1016/j.wace.2015.08.001

Held IM, Soden BJ (2006) Robust responses of the hydrologic cycle to global warming. J Clim 19:5686-5699. https://doi. org/10.1175/JCLI3990.1

Hill HM (2016) World's Biggest Dam Has 'Extremely Dangerous' Low Water Levels. Retrieved from https://www.bloomberg.com/ news/articles/2016-01-08/world-s-biggest-dam-has-extremelydangerous-low-water-levels. Accessed 30 Dec 2017

Huygen J (1989) Estimation of rainfall in Zambia using meteosat-tir data. Winand Staring Centre 1-71. Wageningen, Netherlands

Huynen MM, Martens P, Schram D, Weijenberg MP, Kunst AE (2001) The impact of heat waves and cold spells on mortality rates in the Dutch population. Environ Health Perspect 109:463-470. https://doi.org/10.1289/ehp.01109463

IPCC (2001) Climate change: the scientific basis. Contribution of working group 1 to the third assessment report of the intergovernmental panel on climate change. Int J Epidemiol 32:321. https://doi.org/10.1093/ije/dyg059

IPCC (2007) Climate change 2007: an assessment of the intergovernmental panel on climate change. Clim Change 446:12-17. https://doi.org/10.1256/004316502320517344

IPCC (2012) Managing the risks of extreme events and disasters to advance climate change adaptation. A special report of working groups I and II of the intergovernmental panel on climate change. Cambridge University Press, Cambridge. https://doi. org/10.1017/CBO9781139177245

IPCC (2014) Climate change 2014: synthesis report. Contribution of working groups I, II and III to the fifth assessment report of the intergovernmental panel on climate change. IPCC, Geneva. Retrieved from https://www.ipcc.ch/pdf/assessment-report/ar5/ syr/AR5_SYR_FINAL_SPM.pdf. Accessed 15 Apr 2019

Jupp TE, Cox PM, Rammig A, Thonicke K, Lucht W, Cramer W (2010) Development of probability density functions for future South American rainfall. New Phytol 187:682-693. https://doi. org/10.1111/j.1469-8137.2010.03368.x

Karim MF, Mimura N (2008) Impacts of climate change and sealevel rise on cyclonic storm surge floods in Bangladesh. Glob
Environ Change 18:490-500. https://doi.org/10.1016/J.GLOEN VCHA.2008.05.002

Karl TR, Nicholls N, Ghazi A (1999) CLIVAR/GCOS/WMO workshop on indices and indicators for climate extremes: workshop summary. Clim Change 42:3-7. https://doi. org/10.1023/A:1005491526870

Kendall MG (1975) Rank correlation methods, 4th edn. Oxford University Press, London

Koch H, Vögele S (2009) Dynamic modelling of water demand, water availability and adaptation strategies for power plants to global change. Ecol Econ 68:2031-2039. https://doi.org/10.1016/J. ECOLECON.2009.02.015

Libanda B, Chilekana N (2018) Projection of frequency and intensity of extreme precipitation in Zambia: a CMIP5 study. Clim Res 76(2006):59-72. https://doi.org/10.3354/cr01528

Libanda B, Ogwang BA, Ongoma V, Ngonga C, Nyasa L (2016) Diagnosis of the 2010 DJF flood over Zambia. Nat Hazards 81:189-201. https://doi.org/10.1007/s11069-015-2069-z

Libanda B, Nkolola NB, Chilekana N, Bwalya K (2019) Dominant east-west pattern of diurnal temperature range observed across Zambia. Dyn Atmos Oceans 86:153-162. https://doi. org/10.1016/j.dynatmoce.2019.05.001

Lovino M, Müller O, Berbery E, Müller G (2018) Evaluation of CMIP5 retrospective simulations of temperature and precipitation in northeastern Argentina. Int J Climatol 38:1158-1175

Mann H (1945) Non-parametric tests against trend. Econometrica $13: 245-259$

Mason SJ, Joubert AM (1997) simulated changes in extreme rainfall over Southern Africa. International Journal of Climatology, 17:291-301. doi.org/10.1002/(SICI)10970088(19970315)17:3 < 291::AID-JOC120 > 3.0.CO;2-1

Masselink G, Russell P (2013) Impacts of climate change on coastal erosion. MCCIP Sci Rev. https://doi.org/10.14465/2013.arc09 $.071-086$

McSweeney C, Jones R, Lee R, Rowell D (2015) Selecting CMIP5 GCMs for downscaling over multiple regions. Clim Dyn 44(11-12):3237-3260

Meehl GA, Tebaldi C (2004) More intense, more frequent, and longer lasting heat waves in the 21st century. Science 305:994997. https://doi.org/10.1126/science.1098704

Ministry of Agriculture, Food and Fisheries (MAFF) (1992) A Framework for Agricultural Policies to the year 2000 and beyond

Monteith JL (2007) Evaporation and surface temperature. Q J R Meteorol Soc 107(451):1-27. https://doi.org/10.1002/qj.49710745102

Nkunzimana AB, Jiang T, Wu W, Muhammad Abro I (2019) Spatiotemporal variation of rainfall and occurrence of extreme events over Burundi during 1960 to 2010. Arab J Geosci. https://doi. org/10.1007/s12517-019-4335-y

Ongoma V, Chen H, Gao C, Nyongesa AM, Polong F (2018) Future changes in climate extremes over Equatorial East Africa based on CMIP5 multimodel ensemble. Nat Hazards 90:901-920. https:// doi.org/10.1007/s11069-017-3079-9

Panda DK, Panigrahi P, Mohanty S, Mohanty RK, Sethi RR (2016) The 20th century transitions in basic and extreme monsoon rainfall indices in India: Comparison of the ETCCDI indices. Atmos Res 181:220-235. https://doi.org/10.1016/j.atmosres.2016.07.002

Patz JA, Campbell-Lendrum D, Holloway T, Foley JA (2005) Impact of regional climate change on human health. Nature 438:310-317. https://doi.org/10.1038/nature04188

Pohlert T (2016) Non-parametric trend tests and change-point detection. R Package. https://doi.org/10.13140/RG.2.1.2633.4243

Porja T (2013) Heat waves affecting weather and climate over Albania. J Earth Sci Clim Change 4:4-6. https://doi.org/10.4172/21577617.1000149 
Reason C (2016) Climate of Southern Africa. doi.org/10.1093/ acrefore/9780190228620.013.513

Riahi K, Rao S, Krey V, Cho C, Chirkov V, Fischer G, Rafaj P (2011) RCP 8.5-A scenario of comparatively high greenhouse gas emissions. Clim Change 109:33-57. https://doi.org/10.1007/s1058 4-011-0149-y

Ryan CM, Pritchard R, McNicol I, Owen M, Fisher JA, Lehmann C (2016) Ecosystem services from southern African woodlands and their future under global change. Philo Trans R Soc B Biol Sci 371(1703):20150312. https://doi.org/10.1098/rstb.2015.0312

Sen PK (1985) Estimates of the regression coefficient based on Kendall's tau. Journal of the American Statistical Association 1977:203-208. Retrieved from http://www.jstor.org/stable/22858 91. Accessed 22 Jan 2018

Shoko K, Shoko N (2013) Indigenous weather forecasting systems: a case study of the abiotic weather forecasting indicators for wards 12 and 13 in Mberengwa District Zimbabwe. Asian Soc Sci 9:285-297. https://doi.org/10.5539/ass.v9n5p285

Sillmann JV, Kharin V, Zwiers FW, Zhang X, Bronaugh D (2013) Climate extremes indices in the CMIP5 multi-model ensemble. Part 1: model evaluation in the present climate. J Geophys Res. https ://doi.org/10.1002/jgrd.50203

Spalding MD, Brown BE (2015) Warm-water coral reefs and climate change. Science. https://doi.org/10.1126/science.aad0349

Sylla MB, Giorgi F, Coppola E, Mariotti L (2013) Uncertainties in daily rainfall over Africa: assessment of gridded observation products and evaluation of a regional climate model simulation. Int $\mathbf{J}$ Climatol 33:1805-1817. https://doi.org/10.1002/joc.3551

Taylor KE, Stouffer RJ, Meehl GA (2012) An overview of CMIP5 and the experiment design. Bull Am Meteor Soc 93:485-498. https:// doi.org/10.1175/BAMS-D-11-00094.1
Tomozeiu R, Agrillo G, Cacciamani C, Pavan V (2014) Statistically downscaled climate change projections of surface temperature over Northern Italy for the periods 2021-2050 and 2070-2099. Nat Hazards 72:143-168. https://doi.org/10.1007/s11069-013-0552-y

UN (2002) UN Atlas of the Oceans. Retrieved January 18, 2018, from http://www.oceansatlas.org/

WMO (2015) Meeting of the commission for climatology task team on the definition of extreme weather and climate events. Geneva, Switzerland. Retrieved from https://www.wmo.int/pages/prog/ wcp/ccl/opace/opace2/documents/report-TT-DEWCE-1.pdf. Accessed 1 Jan 2018

WMO (2017) WMO Statement on the State of the Global Climate in 2017 Provisional Release. Retrieved from http://ane4bf-datap 1.s3-eu-west-1.amazonaws.com/wmocms/s3fs-public/ckeditor/ files/2017_provisional_statement_text_-_updated_04Nov2017_1. pdf?7rBjqhMTRJkQbvuYMNAmetvBgFeyS_vQ. Accessed 1 Feb 2018

Yue S, Pilon P, Cavadias G (2002) Power of the Mann-Kendall and Spearman's rho tests for detecting monotonic trends in hydrological series. J Hydrol 259:254-271. https://doi.org/10.1016/S0022 -1694(01),00594-7

Zhang K, Douglas BC, Leatherman SP (2004) Global warming and coastal erosion. Clim Change 64(1-2):41-58. https://doi. org/10.1023/B:CLIM.0000024690.32682.48

Publisher's Note Springer Nature remains neutral with regard to jurisdictional claims in published maps and institutional affiliations. 